\title{
Words from the new editor
}

DOI: $10.17129 /$ botsci.1923

ear members of Sociedad Botánica de México and authors of Botanical Sciences:

It is an honor to accept the invitation of Dr. Luis Hernández, president of the Botanical Society of Mexico (SBM), to be the new editor of our journal. At the same time, I recognize that this endeavor will be a challenge. Botanical Sciences (formerly Boletín de la Sociedad Botánica de México) is currently a well-respected scientific publication, and during the past few years there have been considerable advances in the quality of its edition, content, and regularity. Its open-access distribution via the SBM website has allowed authors from throughout the globe to consider Botanical Sciences as a suitable forum in which to publish their research. For this reason, in recent years various academics from other continents have authored contributions in our journal. These achievements are the result of the vigorous work and insightful changes implemented by my predecessors: Juan Núñez-Farfán, Teresa Terrazas, Victoria Sosa, and chiefly Jorge Meave. All of them have been the architects of changes and updates that have permitted the publication in an electronic format, the inclusion in the Directory of Open Access Journals (DOAJ), the separation of the position of Editor from the Board of Directors of the SBM, the obtainment of external funding, the inclusion in the international index ISI Web of Knowledge, and the journal's hosting within an electronic portal, among others.

For the upcoming period that I will lead, we have outlined new objectives that we hope to fulfill. It is remarkable to recognize the diversity of approaches and proposals that SBM members have, especially young people. We want a journal that can receive the most significant academic production of the society's members, without neglecting of course that we are part of a global community of botanical knowledge. We will accept contributions in English and Spanish, but the editorial committee will evaluate these and request that the authors publish their works in English, if it is more appropriate. To complete my job as Editor, I have assembled a diverse and dedicated editorial committee (with team and section editors), as well as reviewers. However, we have several challenges with regard to international journal rating and indexing systems, the inclusion and permanence in library services, the insertion of metadata, and the inclusion of complete texts in international search engines, among others.

All members of the SBM, and non-members too, who submit a contribution to Botanical Sciences, should understand that editorial work carries a responsibility and is often 
difficult. It is the responsibility of the editorial committee to accept and ensure the quality of the publication. If the journal does not meet ethical and quality standards (including language), then all other aspects of the editorial process will be affected. Therefore, the quality of an academic journal such as Botanical Sciences is the result of the rigor and care of the editorial team (editor, managing editor, reviews editor, section editors, reviewers, and editorial assistant), as well as its international visibility. However, its success also depends on other factors that come into play during the everyday tasks of editorial management.

Botanical Sciences is currently one of the prominent Mexican academic journals in plant sciences with international scope. However, now is the time to reflect on what we want and what we can do to further professionalize the journal so that production and publication processes adhere to the highest international standards.

Salvador Arias, editor 